\title{
When development goes wrong
}

Studying mutants helps our understanding of how we all take shape.

\section{Mutants}

by Armand Marie Leroi

Viking: 2003. 320 pp. \$25.95

\section{Peter Little}

Nature and nurture have a capricious power to alter body form, often with monstrous outcomes. Only relatively recently has it become morally unacceptable to collect and exhibit human examples. At the same time, huge strides have been made in understanding the molecular events that pattern and define the form of living creatures. It is perhaps ironic that this understanding has often been based on the deliberate creation of equally deformed model organisms.

Armand Leroi has realized that our expanding knowledge of the molecular underpinnings of development means that we may now be able to revisit these unfortunate humans, no longer to gape and stare, but to see if we can apply our understanding to the only organism in which we are really interested - ourselves. The result of this realization is his new book, Mutants.

Leroi has an extraordinarily extensive familiarity with a dazzling range of information that stretches from Neolithic sculpture to molecular developmental biology in the pages of Nature in 2002, and he draws on this to detail the remarkable molecular catastrophes that have been visited upon some unfortunate humans. He seeks to relate these cases back to a modern explanation based on molecular developmental biology, and in so doing to illustrate the principles that lie behind our development.

The story unrolls in three critical chapters that cover the control of overall body form. Conjoined twins lead us through the establishment of the three basic tissue types and the power of the 'organizer' to direct their development. Next, the one-eyed Cyclops of Greek mythology and terrible images of its human counterparts lead us to the wonderful elegance and simplicity of the homeotic genes and their ability to specify the identity of body parts. A chapter on limb development and failures to control limb induction then rounds off this most fundamental level of control of body form.

So far, Mutants might sound like yet another textbook, but this could not be further from the truth. What textbook would start a section on limb development with the story of two religious dissenters, Margaret McLaughlin and Margaret Wilson, who were tied to a stake in the River Bladnoch in Scotland and left to be overwhelmed by the rising tide and the estuarine crabs? And what's it got to do with development? You may well

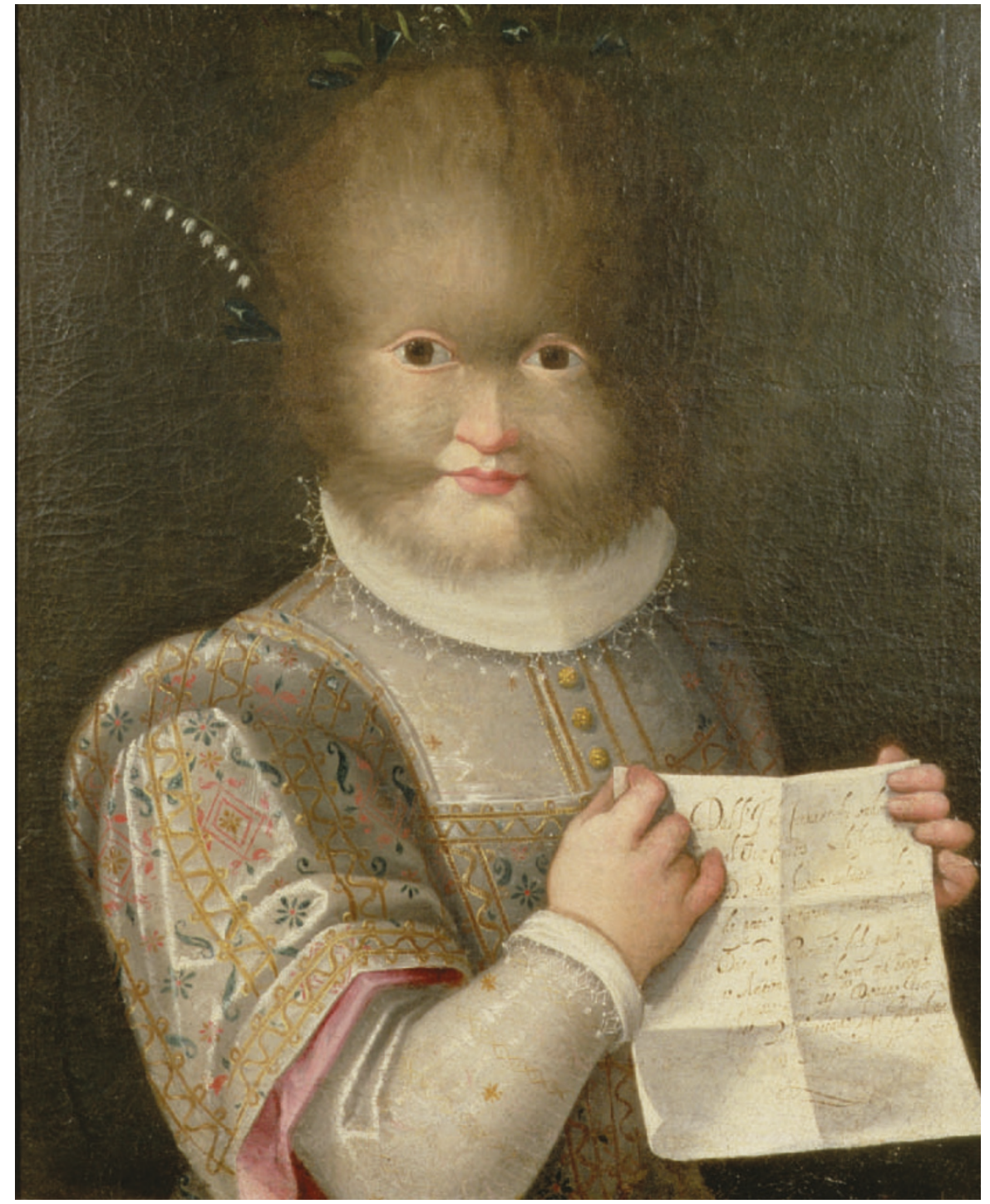

Altered morphology: Lavinia Fontana's Portrait of a Girl Covered in Hair.

wonder. Their executioner was supposedly 'punished' for his cruelty by his children being born with hands like crabs' claws. Leroi uses this story to tease out the controls of limb development through tales of crookfooted Hephaestus, the two-toed Wadoma tribe of Africa, the armless fiddler of Germany, the handless and footless aleijadinhos of Brazil, Le Petite Pepin with his thalidomide-like shortened limbs, and finally even Charles Darwin (for his views on polydactyly). Leroi uses this wild and exotic cast of characters as the basis for discussion.

The next four chapters gallop through the control of skeleton development (or lack of it, in the case of Harry Eastlake, who died at 40 , his normal skeleton encased in another); the control of size (here we find pygmies, giants, monsters and castrato opera singers); gender (illustrated by the amazing observation that hyenas give birth through an enlarged clitoris, and by the tragic suicide of Abel Barbin, born as a girl to die as a man); and, finally, skin and hair, where we meet albinos, piebalds and the hairy ShweMong and his children at home in the Burmese court.

At this point, with only the briefest pause for breath, Leroi charges into the penultimate chapter, on ageing. This is a departure from the more morphological focus of the work so far and, for me, is less exciting. Ageing has all the features of being an innate property of an organism's biological constraints, and I confess to being prejudiced - it is too hard for us right now and is better left alone.

The final chapter, though, is wonderful. 
We all choose, or are driven, to be excited not by all of science itself, but by some more limited domain; Leroi is driven by a fascination with the morphology of race and, more personally still, by the biology of beauty. I too know the effect of a mutation in the MC1R gene, which is responsible for redheads, and I know that it is beautiful. Leroi draws tight his net of wonderful human diversity and gracefully displays its contents, and I am full of admiration for his willingness to build on his declared prejudice.

Despite its subject matter, Mutants is an exquisitely life-enhancing book. It captures what we know of the development of what makes us human, and it recognizes the random tragedy inflicted by nature and nurture. Read the book and you will be exposed to both a scientific world that no longer exists and to that of the twenty-first century. Read it and you will know a tiny part of what it is that has made you the person you are. Read it and enjoy words written carefully, elegantly and with sensibility. Read it and marvel.

Peter Little is at the School of Biotechnology and Biomolecular Science, University of New South Wales, Sydney, New South Wales 2052, Australia.

\section{Watching the Earth move}

\section{Pendulum: Léon Foucault and the Triumph of Science \\ by Amir D. Aczel \\ Atria: 2003. 288 pp. $\$ 25$}

\section{Michael Matthews}

Léon Foucault (1819-1868) is known to millions by virtue of science museums around the world displaying his pendulum. Foucault's pendulum gained even wider recognition as the title of a best-selling novel by Umberto Eco. But although Foucault's name is widely recognized, knowledge about him, even among scientists and historians of science, is thin. This scientific and social biography by Amir Aczel, who has written several popular-science books including Fermat's Last Theorem (Four Walls Eight Windows, 1996), should rectify this problem.

Foucault experienced similar travails to those endured by John Harrison, another pendulum enthusiast and the protagonist of Dava Sobel's best seller Longitude (Walker, 1995). Both men came from outside their country's scientific establishment, both were long rejected by the establishment, both were given recognition by 'royal' decree, and both enjoyed their rightful fame only at the end of their lives. But whereas Harrison was predominantly a technician who worked for 17 years on the construction of a single pendulum clock, Foucault had

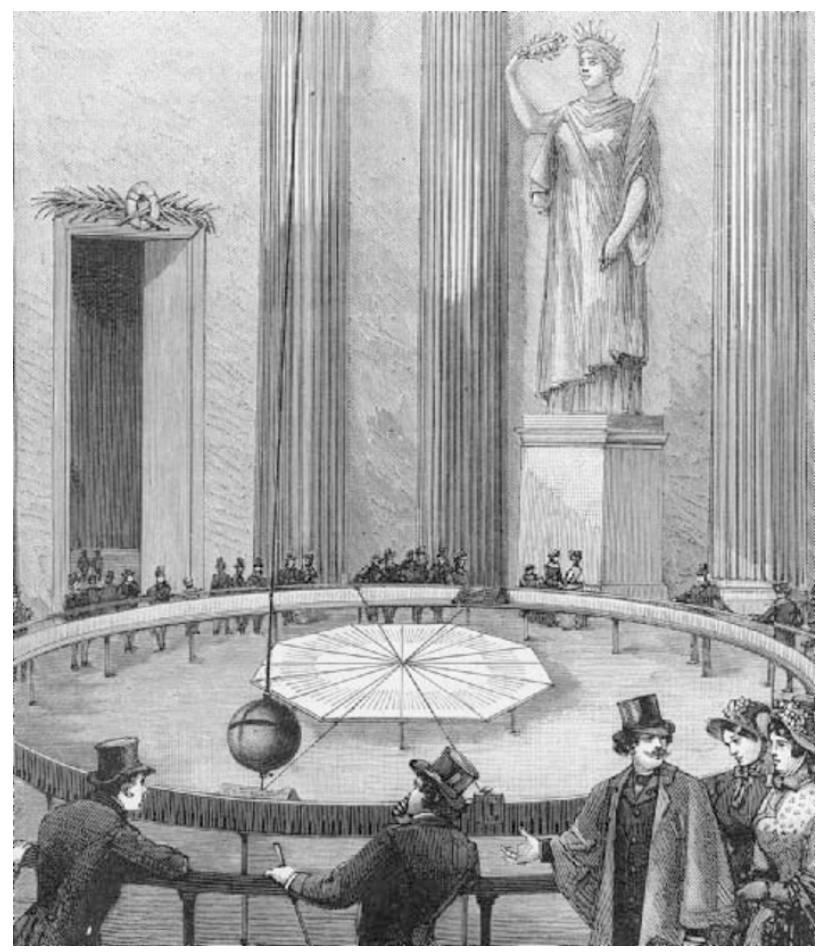

In full swing: Léon Foucault's pendulum revealed the Earth's rotation.

scores of scientists, mathematicians and savants duly gathered behind a wooden balustrade that marked off the oscillation space of an 11-metre heavy pendulum that swung along the markedout Paris meridian. Once the pendulum was set swinging, the Earth moved before the eyes of the audience. The plane of oscillation of the pendulum slowly but perceptibly altered. Foucault's clever handiwork had ensured that there was no torque force on the pendulum, so the only conclusion to be drawn was that the Earth had moved.

This was the first dynamical proof of Earth's rotation - something that had eluded natural philosophers and scientists since Pythagorus and

much wider technical and scientific interests.

As a small boy, Foucault suffered numerous illnesses. One of his eyes was myopic and the other was far-sighted. A friend wrote of him that "the feebleness of his constitution and the slowness that characterized his work made it impossible for him to frequent a college". He could therefore pursue his studies only with help from a devoted tutor, "under the watchful eyes of his mother". But he did have a gift for working with his hands.

The combination of dogged and skilled handiwork with scientific interest and competence were the foundations of his scientific successes. For example, he improved the daguerreotype method to obtain the first ever 'photograph' of the Sun showing its sunspots. He also constructed a massive (190-centimetre) but finely accurate reflecting telescope that was engine-driven to compensate for Earth's rotation; this instrument contributed significantly to Urbain-JeanJoseph Le Verrier's astronomical triumphs. In 1850 Foucault determined the speed of light to be 298,000 kilometres per second, which is within $0.6 \%$ of the current accepted value. And in 1851 he made the world's first gyroscope that could be pointed towards true north, thereafter holding its position and thus being a non-magnetic and superbly accurate compass.

But Foucault's fame rests on his pendulum demonstration, which rightly takes centre stage in Aczel's book. On 2 February 1851, Foucault sent to all known scientists in Paris a simple invitation that read: "You are invited to come to see the Earth turn, tomorrow, from three to five, at the Meridan Hall of the Paris Observatory." The following day,
Aristarchus in the ancient world proposed that it was Earth that rotated, rather than the heavens that rotated around a stationary Earth. Copernicus had resurrected the heliocentric, rotating-Earth theory in 1543; Galileo defended the view in the early seventeenth century; Newton and other leading astronomers and scientists also adopted the position. But with enough determination and conviction, all of their astronomical evidence could be reconciled with the stationary-Earth theory. Tycho Brahe took this option, and so did the Catholic Church, which kept all 'rotating Earth' publications on the Index of Forbidden Books until as late as 1835.

Aczel's book benefits from his study of original sources, including those in the French Academy of Sciences, the French National Library and the Paris Observatory. The book nicely connects Foucault to his political, social and scientific times. It details the generous support that Foucault received from Louis-Napoléon Bonaparte after the scientific establishment had all but ignored him. Aczel rightly highlights the question of why it was that so simple a demonstration of the moving Earth had eluded the roll-call of geniuses who had sought it. And he also asks why the French Academy of Sciences resolutely refused membership to Foucault not only before his demonstration, but for 15 years afterwards.

Michael Matthews is at the School of Education, University of New South Wales, Sydney, Australia. He is the author of Time for Science Education: How Teaching the History and Philosophy of Pendulum Motion Can Contribute to Science Literacy (Kluwer, 2000). 